\title{
Editorial
}

\section{High Entropy Materials: Challenges and Prospects}

\author{
Peter K. Liaw *(D) and Weidong Li * \\ Department of Materials Science and Engineering, University of Tennessee, Knoxville, TN 37996-2100, USA \\ * Correspondence: pliaw@utk.edu (P.K.L.); wli20@utk.edu (W.L.); Tel.: +1-865-974-6356 (P.K.L.)
}

Citation: Liaw, P.K.; Li, W. High Entropy Materials: Challenges and Prospects. Metals 2021, 11, 1643. https://doi.org/10.3390/met11101643

Received: 11 October 2021

Accepted: 14 October 2021

Published: 15 October 2021

Publisher's Note: MDPI stays neutral with regard to jurisdictional claims in published maps and institutional affiliations.

\section{Introduction and Scope}

Entropy is an important concept in thermodynamics, measuring the disorder in a system or, more precisely, the number of possible microscopic configurations of individual atoms or molecules of a system, i.e., microstates. High-entropy materials (HEMs), in terms of entropy, are a class of materials with a higher-than-usual degree of disorder in their microstructures. The high degree of microstructural disorder in these materials implies that they possess simpler microstructures than their low- and medium-entropy counterparts. A representative example is the formation of a single disordered solid solution in a multicomponent alloy system, rather than several phases expected from the Gibbs phase rule.

The high-entropy concept was first proposed in the field of metals in 2004 by Yeh et al. [1], and the relevant materials would later become widely known as high-entropy alloys (HEAs). What interests researchers about HEAs is that the mixture of five or more elements in equal or near-equal atomic proportions could result in a single solid solution phase, which is unexpected given the established metallurgical wisdom. The mix of multiple elements in equal or near-equal atomic proportions also overturns the long-established alloy-making practice of utilizing one principal element and adding others as minor ones for property tuning, thereby creating a drastically huge compositional space for material researchers to work with. The research into the multiple different aspects of HEAs continuously reveals unique microstructures and promising properties [2,3]. All these facts are making HEAs one of the most promising fields of research in the material community.

The high-entropy concept is not limited to the field of metals; its scope includes other materials. High-entropy ceramics, high-entropy polymers, and high-entropy composites are emerging to enrich the HEM family. Predictably, prospects and challenges go hand-inhand in each class of HEMs. This Special Issue has been launched to provide a platform for researchers in this field to report on the prospects and challenges they face in advancing HEM research.

\section{Contributions}

This Special Issue is composed of eight articles, which have been contributed from various branches of HEMs and related fields, including five articles on HEAs, one on high-entropy ceramics and composites, and one on bulk metallic glasses.

In the five articles on HEAs, two focus on refractory HEAs, one designing a singlephase body-centered cubic (bcc) in the Mo-Nb-V-W-Ti system with classical empirical rules and studying their microstructures and mechanical properties accordingly [4], the other exploring the laser beam welding of the $\mathrm{Ti}_{1.89} \mathrm{NbCrV}_{0.56}$ and reporting on the influence of differently configured welds on the microstructure evolution and mechanical properties of the alloy [5]. In addition, there is one article attempting to tailor the composition in the $\left(\mathrm{Fe}_{0.3} \mathrm{Co}_{0.5} \mathrm{Ni}_{0.2}\right)_{100-x}\left(\mathrm{Al}_{1 / 3} \mathrm{Si}_{2 / 3}\right)_{x}$ system to design cost-effective soft magnetic alloys with satisfactory mechanical properties [6], one article statistically analyzing the prevalence of intermetallic (IM) phases of 142 IM-containing HEAs and inspecting the inheriting relation of the IM phases in HEAs with what were reported in their binary and tertiary subsystems [7], and one article reviewing the potential of HEAs as biomaterials [8]. 
The article on high-entropy ceramics reports on the steps of making ( $\mathrm{Hf}-\mathrm{Ta}-\mathrm{Ti}-\mathrm{Nb}-\mathrm{V}) \mathrm{C}$ and (Ta-Ti-Nb-V-W)C high-entropy carbides, and then compositing them with the 19.2 vol\% Co binder to make hard metals (also known as cemented carbides) as potential cutting tool materials [9]. Researchers also mix up the $\mathrm{TiC}$ and FeCoNiCuAl HEA with mechanical alloying and sinter the mixture into TiC-reinforced FeCoNiCuAl HEA composites with spark plasma sintering, whose hardness and wear performance are largely improved [10]. Lastly, a low-cost bulk metallic glass, $\mathrm{Zr}_{58} \mathrm{Cu}_{15.46} \mathrm{Ni}_{12.74} \mathrm{Al}_{10.34} \mathrm{Nb}_{2.76} \mathrm{Y}_{0.5}$ (at\%), is prepared using the industrial grade $\mathrm{Zr}$ and its high-cycle fatigue behavior is investigated [11].

\section{Conclusions and Outlook}

Though eight articles were eventually accepted for publication, this Special Issue covers a wide range of topics in the field of high-entropy materials, the majority of which cover different aspects of high-entropy alloys, while high-entropy ceramics, high-entropy composites, and bulk metallic glasses are also covered. The published work aims to inspire continued research in the respective sub-fields. We look forward to seeing more interesting and inspiring research following this Special Issue, advancing each sub-field and the wider field of high-entropy materials as a whole.

This Special Issue could not be a success without the contribution of committed authors, responsive reviewers, and the diligent Metals Editorial Office, especially Toliver Guo, who facilitates everything with his patience and professionalism. Thanks to all authors, reviewers, and Metals staff for their dedication. Credit goes to every single person engaged in this endeavor.

Funding: This research received no external funding.

Conflicts of Interest: The authors declare no conflict of interest.

\section{References}

1. Yeh, J.W.; Chen, S.K.; Lin, S.J.; Gan, J.Y.; Chin, T.S.; Shun, T.T.; Tsau, C.H.; Chang, S.Y. Nanostructured high-entropy alloys with multiple principal elements: Novel alloy design concepts and outcomes. Adv. Eng. Mater. 2004, 6, 299-303. [CrossRef]

2. Li, W.; Liaw, P.K.; Gao, Y. Fracture resistance of high entropy alloys: A review. Intermetallics 2018, 99, 69-83. [CrossRef]

3. Li, W.; Xie, D.; Li, D.; Zhang, Y.; Gao, Y.; Liaw, P.K. Mechanical behavior of high-entropy alloys. Prog. Mater. Sci. $2011,118,100777$. [CrossRef]

4. Regenberg, M.; Hasemann, G.; Wilke, M.; Halle, T.; Krüger, M. Microstructure Evolution and Mechanical Properties of Refractory Mo-Nb-V-W-Ti High-Entropy Alloys. Metals 2020, 10, 1530. [CrossRef]

5. Panina, E.; Yurchenko, N.; Zherebtsov, S.; Stepanov, N.; Salishchev, G.; Ventzke, V.; Dinse, R.; Kashaev, N. Laser Beam Welding of a Low Density Refractory High Entropy Alloy. Metals 2019, 9, 1351. [CrossRef]

6. Zhang, Y.; Zhang, M.; Li, D.; Zuo, T.; Zhou, K.; Gao, M.C.; Sun, B.; Shen, T. Compositional Design of Soft Magnetic High Entropy Alloys by Minimizing Magnetostriction Coefficient in $\left(\mathrm{Fe}_{0.3} \mathrm{Co}_{0.5} \mathrm{Ni}_{0.2}\right)_{100-x}\left(\mathrm{Al}_{1 / 3} \mathrm{Si}_{2 / 3}\right)_{x}$ System. Metals 2019, 9, 382. [CrossRef]

7. Tsai, M.-H.; Tsai, R.-C.; Chang, T.; Huang, W.-F. Intermetallic Phases in High-Entropy Alloys: Statistical Analysis of their Prevalence and Structural Inheritance. Metals 2019, 9, 247. [CrossRef]

8. Castro, D.; Jaeger, P.; Baptista, A.C.; Oliveira, J.P. An Overview of High-Entropy Alloys as Biomaterials. Metals 2021, 11, 648. [CrossRef]

9. Pötschke, J.; Dahal, M.; Vornberger, A.; Herrmann, M.; Michaelis, A. Production and Properties of High Entropy Carbide Based Hardmetals. Metals 2021, 11, 271. [CrossRef]

10. Zhu, T.; Wu, H.; Zhou, R.; Zhang, N.; Yin, Y.; Liang, L.; Liu, Y.; Li, J.; Shan, Q.; Li, Q.; et al. Microstructures and Tribological Properties of TiC Reinforced FeCoNiCuAl High-Entropy Alloy at Normal and Elevated Temperature. Metals 2020, 10, 387. [CrossRef]

11. Zhou, S.; Zhang, T.; Li, L.; Yang, J.; Zhang, M.; Wang, C.; Zhang, Y. Fatigue Behavior of $\mathrm{Zr}_{58} \mathrm{Cu}_{15.46} \mathrm{Ni}_{12.74} \mathrm{Al}_{10.34} \mathrm{Nb}_{2.76} \mathrm{Y}_{0.5} \mathrm{Bulk}$ Metallic Glass Fabricated by Industrial-Grade Zirconium Raw Material. Metals 2021, 11, 187. [CrossRef] 